Celal Bayar University Journal of Science

\title{
Fenoxycarb Effects 7th instar Galleria mellonella Larvae by Triggering Extra Larval Stages
}

\author{
Esen Poyraz Tınartaş ${ }^{1 *(D)}$, Nesrin Ebru Göncü ${ }^{2}(\mathrm{D}), \mathrm{Kamil} \mathrm{Koç}^{1}$ (iD) \\ ${ }^{1}$ Manisa Celal Bayar University, Faculty of Science and Arts, Department of Biology, Manisa, Turkey \\ ${ }^{2}$ Ege University, Faculty of Science, Department of Biology, İzmir, Turkey \\ * esen.poyraz@cbu.edu.tr \\ *Orcid: 0000-0001-7386-2136
}

Received: 16 November 2020

Accepted: 3 May 2021

DOI: $10.18466 /$ cbayarfbe. 823562

\begin{abstract}
Insect growth regulators are specific chemicals with hormonal effects on insects and these types of chemicals target to reduce the nonspecific effects of pesticides on nature and living things. In this study, we investigated the effects of one of the insect growth regulators, fenoxycarb which mimics the juvenile hormone action, on the growth of a harmful lepidopteran species Galleria mellonella, and it's some developmental parameters. For this purpose, fenoxycarb was applied on day 0 of 7 th instar larvae of the greater wax moth, Galleria mellonella. The treatment with $100 \mathrm{ng}$ fenoxycarb had no developmental effect on Galleria mellonella larvae. The treatment with relatively high doses of fenoxycarb on day 0 induced the supernumerary larvae formation of $99 \%$ and larvae which molted extra larval instar formed healthy pupae in the ratio of $98-99 \%$. Consequently, the effects of fenoxycarb on Galleria mellonella larvae occurred in a dose-dependent manner. Although fenoxycarb is a potent insect growth regulator, late Galleria mellonella larvae are not susceptible to this chemical, unlike some other Lepidopter insect species.
\end{abstract}

Keywords: Development, Fenoxycarb, Galleria mellonella, Juvenile hormone.

\section{Introduction}

Insect growth regulators are produced to develop more specific chemicals against harmful insects that target to reduce the nonspecific effects of pesticides on nature and living things and they show hormonal effects on insects. Most insect growth regulators today are juvenile hormone $(\mathrm{JH})$ analogues, which mimic the mechanism of action of $\mathrm{JH}$. $\mathrm{JH}$ provides the continuity of larval characters for holometabolous insects [1]. $\mathrm{JH}$ or $\mathrm{JH}$ analogues applications disturb the endocrine balance of many insects and finally induces abnormal development [1-4]. No synthetic JH analogue can instantly kill the target organism with a direct toxic effect. Instead, it leads to developmental abnormalities, causing insufficiency in development and reproductive functions [5, 6]. Fenoxycarb, 0-ethyl N-(2-(4-phenoxyphenoxy) ethyl) carbamate, is one of the most effective chemicals among these $\mathrm{JH}$ analogues [1].

Galleria mellonella, the greater wax moth, is a harmful lepidopteran species that causes economic losses in the beekeeping industry because its larva feeds on combs, and also their larvae and pupae are one of the oldest experimental models used in insect physiology [7-10]. Until now, there has been no quantitative report that has examined the responses of the larvae of Galleria mellonella to treatments with fenoxycarb. The present study attempted to clarify the response of Galleria mellonella to different doses (100 $\mathrm{ng}$ to $10 \mu \mathrm{g})$ of fenoxycarb during the last larval stage. For this purpose, molting, growth, and some survival parameters after treatments were evaluated and statistical analyses were carried out depending on application doses.

\section{Materials and Methods}

Galleria mellonella larvae were reared at $30 \pm 0.5{ }^{\circ} \mathrm{C}$, $60 \pm 5 \%$ relative humidity and constant darkness in the incubator on a diet containing bran (420 g), honeycomb $(160 \mathrm{~g})$, honey $(150 \mathrm{ml})$, glycerol $(150 \mathrm{ml})$ and distilled water $(30 \mathrm{ml})$ modified from Bronksill [11].

Eggs were collected every day. During the feeding period, larvae were classified in every 24-hours. The first 24 hours were named as day 0 (Figure 1c- d). At larval-pupal metamorphosis, the classification of larval development was performed according to the 
morphology and morphological characteristics of the migration of the pigments from the stemmata [12]. This retraction of pigments occurs in several stages (S1-S5) under hormonal factors $[12,13]$. Also, the head capsule width of the larvae was measured by millimeter ocular and was statistically evaluated. After pupal molting, pupae were also classified every 24 hours.

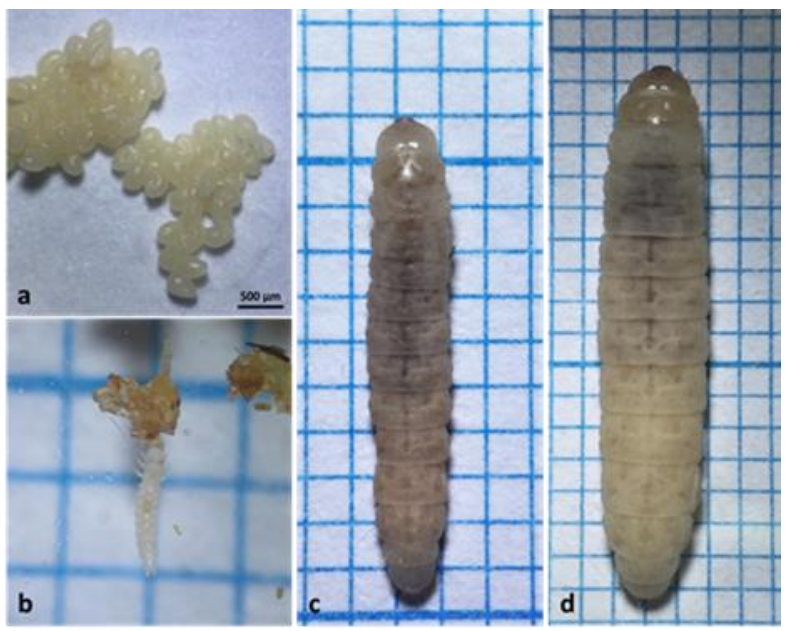

Figure 1. Different developmental stages of Galleria mellonella larvae; a) Galleria mellonella eggs, d) Feeding early larva of Galleria mellonella, c) 6th instar newly ecdysis larva, d) 7th instar newly ecdysis larva.

On day 0 of 7 . instar, every ten larvae were topically treated with eight different doses of fenoxycarb (100 ng, $250 \mathrm{ng}, 500 \mathrm{ng}, 750 \mathrm{ng}, 1 \mu \mathrm{g}, 2 \mu \mathrm{g}, 5 \mu \mathrm{g}$, and $10 \mu \mathrm{g}$ ) (Fluka, 34343) in 2,5 $\mu \mathrm{l}$ acetone (solvent) with a micropipette along the dorsal midline. Control larvae were treated with an equal amount $(2.5 \mu \mathrm{l})$ of solvent without fenoxycarb. The groups treated with fenoxycarb were cultured in different incubators and laboratories to prevent any contamination with the control group. The larvae that remained in the 7 th instar more than 20 days were defined as "dauer larvae" [1, 14]. Each experimental procedure was performed three times.

Ten randomly selected larvae and/or pupae from groups were weighed from day 0 of the 7 th instar to the end of the pupal stage in 24 hours intervals at the same time each day. Analyses of the data were carried out by using SPSS 20.00 software (IBM) $\quad(p<0.05$ level Mann Whitney's U-test).

\section{Results and Discussion}

Hemolymph $\mathrm{JH}$ levels are low at the beginning of the last larval stage to provide a pupal commitment of the insect body. Moreover, this period is extremely sensitive to $\mathrm{JH}$ applications [3, 15]. In this study, fenoxycarb was applied at the beginning of the last larval stage to evaluate the sensitivity of Galleria mellonella to the various levels of $\mathrm{JH}$ presence.

Control group larvae were fed for three and a half days (78-84 hours) and then terminate feeding activity and reached the highest weight values $(310 \mathrm{mg}$ ) at $78-84$ hour period from the beginning of the 7 th instar (S1) as similarly reported by Beck [16]. Wandering and cocoon spinning (S1-S5) ranged from 2 and 3 days, 99\% of the larvae developed normally to the pupal stage. A gradual decrease in weight was observed until the larval-pupal ecdysis. Increasing silk secretion, degeneration of tissues, and organs such as the silk gland and intestine which occupy large volumes and space in the body should be the main reasons for this decline. The pupal period lasted 7 days.

No appreciable difference was found in insects treated with a dose of $100 \mathrm{ng}$ fenoxycarb per larvae when compared with control larvae. Application of doses among 250-750 ng caused to stop feeding activity resulting in growth deficiency in 5\% of larvae, $3 \%$ of larvae died in these groups. Extra larval molting occurred in the ratio of between $35-65 \%$ (Table 1). 27$47 \%$ of larvae showed a prolonged larval stage of 1-2 days and then pupated following a normal course (Figure 2a). Previous studies showed that low and moderate doses of juvenoids caused a significant prolongation of the last larval stages in Holometabola [17] and also Galleria mellonella [2]. These differences may be due to differences in the greater wax moth strain used, the rearing conditions, or the chemical factors used because these factors have been shown to influence the actions of $\mathrm{JH}$ analogues [1].

The last larval stage of Galleria mellonella was sensitive to higher doses of fenoxycarb (1-10 $\mu \mathrm{g})$ and caused supernumerary molt. $5 \mu \mathrm{g}$ and $10 \mu \mathrm{g}$ doses caused extra larval ecdysis occurred synchronously on day 5. Extra larval molting was observed between $95 \%$ and $97 \%$ (Figure 2b). 8th instar larvae pupated normally in the ratio of $99 \%$ and they were morphologically normal. (Table 1). Similarly, early in the last larval instar, the implantation of active corpora allata results in supernumerary larval ecdysis in Galleria mellonella [18]. The effect of $\mathrm{JH}$ and $\mathrm{JH}$ analogues is due to interference with the physiological programming of the secretory functions of the prothoracic glands and the modification of the prothoracic-tropic brain activity [2]. Fenoxycarb treatments may have caused ecdysteroid secretion, so that new larval-larval molting may have been triggered due to high levels of $\mathrm{JH}$ and 20hydroxyecdysone in the hemolymph. The larval-pupal intermediate form was detected in $1-2 \%$ of larvae (Figure 2c). After treatments of $\mathrm{JH}$ and $\mathrm{JH}$ analogues, prolongation of larval stages, larval-pupal intermediate formation, dauer larva formation, and mortality were observed in different ratios in Epiphyas postvittana [19], Ephestia kuehniella [5], Bombyx mori [1, 20]. Extra larval molting was stated in a ratio of $30 \%$ in Ostrinia nubilalis [21, 22]. 
Table 1. Effects of fenoxycarb on the development of Galleria mellonella larvae

\begin{tabular}{|c|c|c|c|c|c|c|c|}
\hline $\begin{array}{l}\text { Dosage } \\
\text { (in } 2.5 \mu \mathrm{l} \\
\text { acetone) }\end{array}$ & $\begin{array}{l}\text { Number } \\
\text { of } \\
\text { treated } \\
\text { larvae }\end{array}$ & $\begin{array}{l}\text { Prolongation } \\
\text { of last larval } \\
\text { instar }\end{array}$ & $\begin{array}{l}\text { Dauer } \\
\text { larvae } \\
(\%)\end{array}$ & $\begin{array}{l}\text { Darkened } \\
\text { and dead } \\
(\%)\end{array}$ & $\begin{array}{l}\text { Poorly } \\
\text { development } \\
\text { and death }(\%)\end{array}$ & $\begin{array}{l}\text { Extra } \\
\text { larval } \\
\text { molting } \\
(\%)\end{array}$ & $\begin{array}{l}\text { Pupation } \\
\text { after extra } \\
\text { larval } \\
\text { molting }(\%)\end{array}$ \\
\hline Controls & 30 & - & - & - & - & - & - \\
\hline $100 \mathrm{ng}$ & 30 & - & - & - & - & - & - \\
\hline $250 \mathrm{ng}$ & 30 & 1-2 days & 10 & 3 & 5 & 35 & 98 \\
\hline $500 \mathrm{ng}$ & 30 & 1-2 days & 10 & 3 & 5 & 42 & 98 \\
\hline $750 \mathrm{ng}$ & 30 & 1-2 days & - & 3 & 5 & 65 & 98 \\
\hline $1 \mu \mathrm{g}$ & 30 & - & - & 2 & 3 & 95 & 99 \\
\hline $2 \mu \mathrm{g}$ & 30 & - & - & 2 & 3 & 95 & 99 \\
\hline $5 \mu \mathrm{g}$ & 30 & - & - & 1 & 2 & 97 & 99 \\
\hline $10 \mu \mathrm{g}$ & 30 & - & - & 1 & 2 & 97 & 99 \\
\hline
\end{tabular}

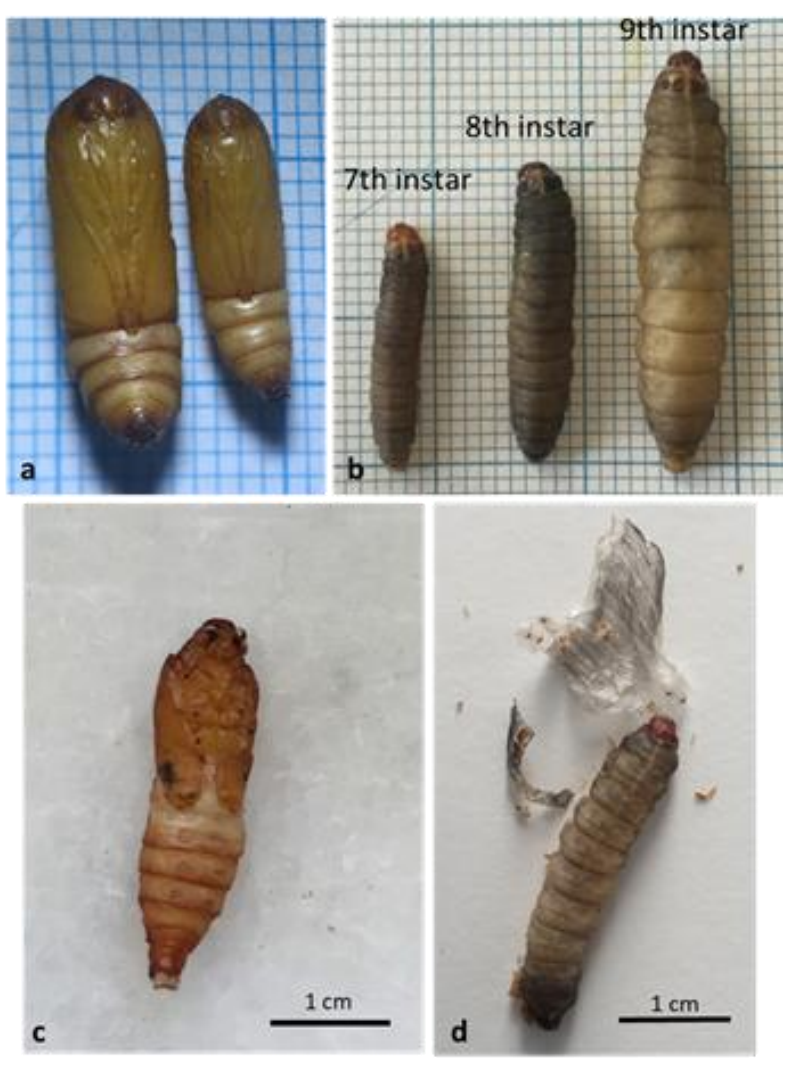

Figure 2. Galleria mellonella larvae and pupae; a) Normally pupated Galleria mellonella, b) Supernumerary larvae of Galleria mellonella, c) Larvalpupal intermediate pupa formation after 8th instar, d) 9th instar larva molted partially.

The growth rate of larvae is defined during the development period by measuring the head capsule width of the samples taken from the population [8]. We determined that the last larval instar head capsule width is $2000 \mu \mathrm{m}$, similarly in Beck [8]. Measurements of $2264.6 \mu \mathrm{m}$ and $2667.1 \mu \mathrm{m}$ of head capsule width in different developmental stages (extra larval stages) also proved that fenoxycarb could affect Galleria mellonella larvae by molting more than once (Student T-Test, $\mathrm{p}<0.05$ ) (Figure 3a).
Measuring the body weights of larvae is also an important parameter in determining the growth rate of larvae [8]. Larvae treated with $5 \mu \mathrm{g}$ of fenoxycarb were fed for the first 4 days and total body weights gradually increased, but this increase was found to be statistically lower than the control group larvae (Mann Whitney's U-test, p<0.05) (Figure 3). Feeding inhibition is a general behavior of insects that comes in contact with various harmful agents [23].

The larvae of the 8th instar were fed for 8 days actively and showed a continuous and significant increase in weight until the 8th day (8-8) (Figure 3c). Sehnal [24] reported similarly weight values in super larvae produced by corpora allata implantation. Between days 8 and 11, their feeding activities decreased or stopped, and weight gain slowed statistically (Mann Whitney's U-test, $\mathrm{p}<0.05)$. The deceleration in the weight gain is thought to be a result of suppression of nutritional activity with excessive growth in animal size and, also the tracheal system probably does not adapt to these changes [25]. The maximum bodyweight a larva can reach and the weight gain that can be achieved in a single larval stage are species-specific $[2,25]$ and this value is not affected by $\mathrm{JH}$ and $\mathrm{JH}$ analogues [2]. These phenomena restrict the growth of insects. Larvae, when they reached 200-300 mg cut off from the feeding in normal development [16], but in some records, this weight could be $590 \mathrm{mg}[2,8]$, and larval growth is terminated irreversibly [2]. In our study, the ecdysis of the larval-pupal was observed near the known upper limit. The average weight of the 8th instar larvae was $596 \mathrm{mg}$ and the lowest value was $410 \mathrm{mg}$. All these findings clarify the cause of feeding and growth inhibition and death in the 9th instar.

Pigment migration, which is the main characteristic of the S1- S5 stages, was not observed in S1 and S2 in the 8th larval instar larvae, which is why the distinction between S1 and S2 was not appropriate in this group. Their developmental stages in the graphs were edited every 24 hours up to S3. At the end of day 11, the spinning behavior began following the gut purge and the 
total body weight decreased continuously, for the same reason as the control group. The pupal bodyweight of the group treated with fenoxycarb was significantly higher than that of the control group all day (Mann
Whitney's U-test, $\mathrm{p}<0.05$, Figure $3 \mathrm{~d}$ ). Pupal molting occurred within 2-3 days and the pupal stage lasted for 7 days as in the control group.
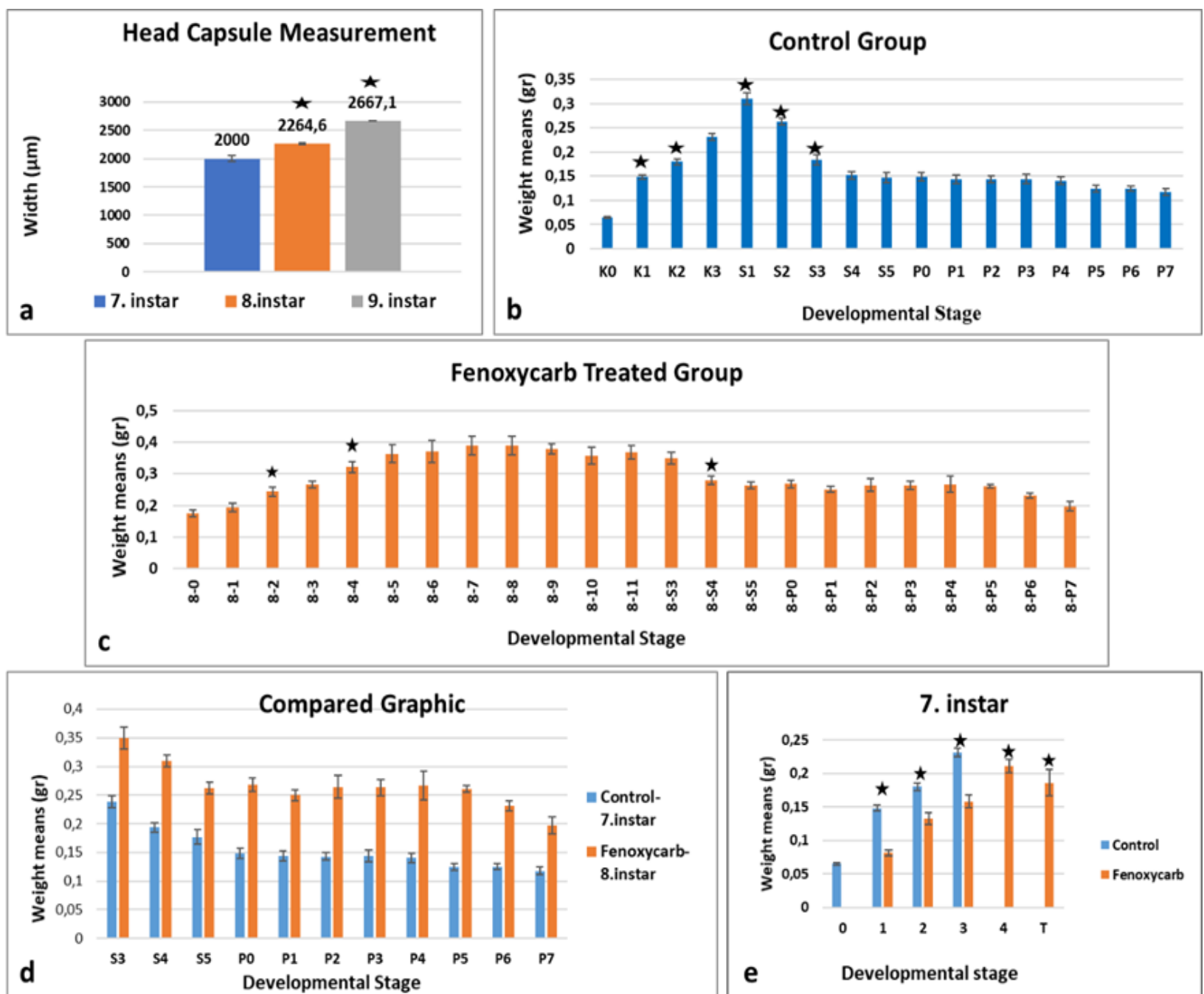

Figure 3. Weight average and head capsule measurement of control and $5 \mu \mathrm{g}$ fenoxycarb treated groups; a) Head capsule measurements of control and $5 \mu \mathrm{g}$ fenoxycarb treated group, b) The average of control group weight, c) The weight average of $5 \mu \mathrm{g}$ fenoxycarb treated group, d) Similar developmental stages of the control group and $5 \mu \mathrm{g}$ fenoxycarb treated group were compared according to their weight changes, e) Comparison of the control group and $5 \mu \mathrm{g}$ fenoxycarb treated group 7th instar values, T: Transition day from, the bars indicate standard errors. The asterisks indicate the statistically significant differences compared to the previous development stage $(\mathrm{p}<0.05)$. S1$\mathrm{S} 5$ represents the stages of development based on the retraction of pigments from stemmata, $\mathrm{P} 0-7$ represents the pupal days.

\section{Conclusion}

In comparison to other Lepidopteran species such as Bombyx mori and Ephestia kuehniella and when applied doses are considered, Galleria mellonella is found to be highly resistant to the fenoxycarb at the beginning of the last larval stage. Relatively high doses $(5-10 \mu \mathrm{g})$ have possibly stimulated the secretion activity of the prothoracic glands and triggered the extra larval ecdysis. However, applications did not affect pupal development and resulted in healthy adults and a new generation developed from their eggs was also healthy. These results clearly showed that fenoxycarb will be not a suitable agent for the biological control of this insect.

\section{Acknowledgment}

We would like to thank the Manisa Celal Bayar University Scientific Research Projects Coordination Unit (BAP) for supporting this study under project number 2014-013. This work was presented at the 
Ecology 2018 Symposium (19-23 June 2018, Kastamonu Turkey) as an oral presentation.

\section{Author's Contributions}

Esen Poyraz Tinartaş: Drafted and wrote the manuscript, carried out the experiment, and evaluated results.

Nesrin Ebru Göncü: Assisted in analytical analysis on the structure, supervised the experiment's progress, result interpretation, and helped in manuscript preparation.

Kamil Koç: Conceived the presented experiment and supervised the findings of this work.

\section{Ethics}

There are no ethical issues after the publication of this manuscript.

\section{References}

1. Kamimura, M, Kiuchi, M. 1998. Effects of a juvenile hormone analog, fenoxycarb, on 5th stadium larvae of the silkworm, Bombyx mori (Lepidoptera: Bombycidae). Applied Entomology and Zoology; 33(2): 333-338.

2. Ciemior, KE, Sehnal, F, Schneiderman, HA. 1979. Molting, Growth and Survival of Galleria mellonella L. (Lep, Pyralidae) Treated with Juvenoids. Zeitschrift Fur Angewandte Entomologie-Journal of Applied Entomology; 88(4): 414-425.

3. Silhacek, DL, Oberlander H. 1975. Time-dosage studies of juvenile hormone action on the development of Plodia interpunctella. Journal of insect physiology, 21(1), 153-161.

4. Dedos, SG, Szurdoki, F, Székács, A, Shiotsuki, T, Hammock BD, Shimada, J, Fugo, H. 2002. Fenoxycarb levels and their effects on general and juvenile hormone esterase activity in the hemolymph of the silkworm, Bombyx mori. Pesticide Biochemistry and Physiology, 73(3): 174-187.

5. Grenier, S, Grenier AM. 1993. Fenoxycarb, a fairly new Insect Growth Regulator: Review of its effects on insects. Annals of Applied Biology; 122(2): 369-403.B

6. Beckage, NE, Rechcigl, J, Rechcigl, N. 2000. Insect growth regulators. Biological and biotechnological control of insect pests, 123-137.

7. Karlson, P. 1956. Biochemical studies on insect hormones Academic Press: In Vitamins \& Hormones; 14: 227-266.

8. Beck, SD. 1960. Growth and Development of The Greater Wax Moth, Galleria mellonella (L.) (Lepidoptera: Galleriidae). Visconsin Academy of Sciences, Arts and Letters; 49: 137-148.

9. Sehnal, F, Meyer, AS. 1968. -Larval-pupal transformation: control by juvenile hormone. Science; 159(3818): 981-4.

10. Richman, K, Oberlander, H. 1971. -Effects of fat body on $\alpha$ ecdysone induced morphogenesis in cultured wing disks of the wax moth, Galleria mellonella. Journal of Insect Physiology; 17(2): 269-276.

11. Bronskill, JA. 1961. A cage to simplify the rearing of the greater wax moth, Galleria mellonella (Lepidoptera: Pyralidae). Journal the Lepidopterists' Society; 15: 102-104.
12. Uwo, MF, Ui-Tei, K, Park, P, Takeda, M. 2002. Replacement of midgut epithelium in the greater wax moth, Galleria mellonella during larval-pupal moult. Cell Tissue Research; 308(2): 319-31.

13. Jindra, M, Riddiford, LM. 1996. Expression of ecdysteroidregulated transcripts in the silk gland of the wax moth, Galleria mellonella. Development genes and Evolution; 206(5): 305-314.

14. Sehna,1 F, Janda, V, Němec, V. 1983. Composition, synthetic and cytolytic activities of Galleria mellonella silk glands during the last-larval instar under the action of juvenile hormone. Journal of Insect Physiology; 29(3): 237-248

15. Retnakaran, A. 1973. Hormonal induction of supernumerary instars in the spruce budworm, Choristoneura fumiferana (Lepidoptera: Tortricidae). The Canadian Entomologist; 105(3): 459-461.

16. Beck S. D., 1970. -Neural and Hormonal Control of Pupation in Galleria mellonella (Lepidoptera: Galleriidae). Annuals of the Entomological Society of America. 63(1): 144-149.

17. Sehnal, F, Metwall, MM, Elbie, I. 1976. Reactions of immature stages of noctuid moths to juvenoids. Z. ang. Ent; 81, 85-102.

18. Sehnal, F. 1968. Influence of the corpus allatum on the development of internal organs in Galleria mellonella L. Journal of Insect Physiology; 14(1), 73-85.

19. Singh, P, Dugdale, J. 1979. Morphogenetic and physiologica effects of a juvenile hormone analogue on the light brown apple moth, Epiphyas postvittana (Lepidoptera: Tortricidae). New Zealand Journal of Zoology; 6: 381-387.

20. Goncu, E, Parlak, O. 2012. The effect of the juvenile hormone analog, fenoxycarb, on ecdysone receptor B1 expression in the midgut of Bombyx mori during larval-pupal metamorphosis. Folia Histochemistry Cytobiology; 50(1): 52-7.

21. Fujiwara, H, Ogai, S. 2001. Ecdysteroid-induced programmed cell death and cell proliferation during pupal wing development of the silkworm, Bombyx mori. Development Genes \& Evolution; 211(3).

22. Gadenne, C, Grenier, S, Plantevin, G, Mauchamp, B. 1991 Effects of a juvenile hormone mimetic, fenoxycarb, on postembryonic development of the European corn borer, Ostrinia nubilalis. Hbn. Experientia; 46(7): 744-747.

23. Leonardi, MG, Cappellozza, S, Ianne, P, Cappellozza, L, Parenti, P, Giordana, B. 1996. Effects of the topical application of an insect growth regulator (fenoxycarb) on some physiological parameters in the fifth instar larvae of the silkworm Bombyx mori. Comparative Biochemistry and Physiology Part B: Biochemistry and Molecular Biology; 113(2), 361-365.

24. Sehnal, F. 1971. Juvenile hormone action and insect growth rate Endocrinologia Experimentalis; 5: 29-33.

25. Callier, V, Nijhout, HF. 2011. Control of body size by oxygen supply reveals size-dependent and size-independent mechanisms of molting and metamorphosis. Proceedings of the National Academy of Sciences of the United States of America; 108(35): 14664-14669. 